\title{
Examining the determinants of global and local price passthrough in cereal markets: evidence from DCC-GJR-GARCH and panel analyses
}

\author{
Jin Guo and Tetsuji Tanaka
}

* Correspondence: kaku@econ. setsunan.ac.jp

Department of Economics, Setsunan University, 17-8 Ikedanakamachi, Neyagawa, Osaka 572-0074, Japan

\begin{abstract}
Existing literature has not yet identified the common determinants of price volatility transmission in agricultural commodities from international to local markets and has rarely investigated the role of self-sufficiency measures in the context of national food security. We analyzed several factors to determine the degree of volatility transmission in wheat, rice and maize prices between world and domestic markets using GARCH models with dynamic conditional correlation specifications and panel feasible generalized least square models. Our findings indicate that a grain autarky system can reduce volatility passthroughs for three grain commodities. While the substitutive commodity consumption behaviour between maize and wheat buffers the volatility transmissions of both, rice does not function as a transmission-relieving element for the volatility implying that rice is not a substitute for wheat or maize consumption; grain consumption proves a more effective substitute than cereal selfsufficiency for insulating passthroughs from global markets. These findings may help the governments of developing nations to protect their domestic food markets from the uncertain movements of foreign markets and may thus improve food security.
\end{abstract}

Keywords: Volatility transmission, Grain self-sufficiency, Food security

JEL classification: Q18, Q17, Q02

\section{Background}

Global food price volatilities have worsened food access for households in recent years, especially in low-income countries (Ivanic and Martin 2008), provoking societal and political instability in various regions (see Fig. 1) (Bellemare 2014). ${ }^{1}$ For instance, the Prime Minister of Haiti, Jacques Edouard Alexis, was forced to resign because the price of rice in the nation spiked and remained high (Delva and Loney 2008). Although there is no consensus among researchers about the causes behind global food market 'storms', biofuel production, yield variability by weather conditions, export restrictions,

${ }^{1}$ Bellemare (2014) econometrically reveals a relationship between food prices and social unrest, such as food riots.

(c) The Author(s). 2020 Open Access This article is licensed under a Creative Commons Attribution 4.0 International License, which permits use, sharing, adaptation, distribution and reproduction in any medium or format, as long as you give appropriate credit to the original author(s) and the source, provide a link to the Creative Commons licence, and indicate if changes were made. The images or other third party material in this article are included in the article's Creative Commons licence, unless indicated otherwise in a credit line to the material. If material is not included in the article's Creative Commons licence and your intended use is not permitted by statutory regulation or exceeds the permitted use, you will need to obtain permission directly from the copyright holder. To view a copy of this licence, visit http://creativecommons.org/licenses/by/4.0/. 


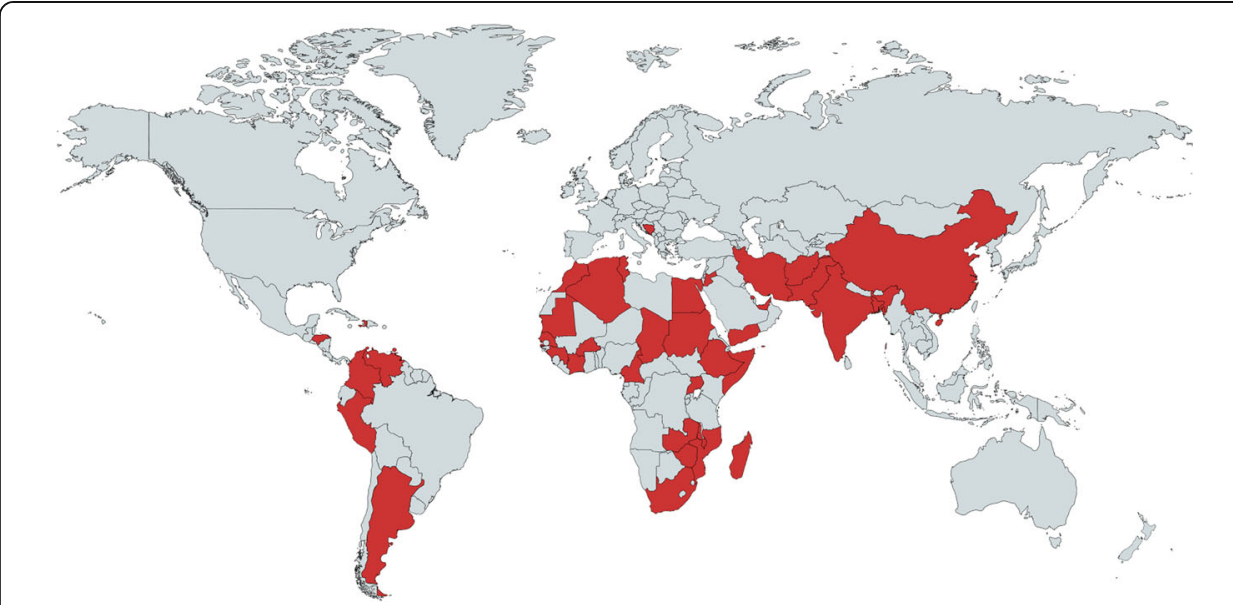

Fig. 1 Food riots between 2007 and 2014 (shown in red). Source: authors' work based on the food riot dataset of the World Bank

high energy prices and financial speculation are widely perceived as the major driving factors (Abbott and Borot de Battisti 2011; Headey and Fan 2008; Gutierrez 2017; Lagi et al. 2011; Tanaka et al. 2012; Trostle 2008; von Braun 2008). Given the international food situation, impoverished nations must urgently implement countermeasures against food price transmissions from extraneous markets in order to calm their internal markets.

Food prices were more volatile from 2007 to 2010 than they were from 2003 to 2006 (Minot 2011). Price volatility affects producers with risk-aversion preferences, making it more difficult for farmers to determine the optimal time at which to sell their commodities; this can lead to the misallocation of inputs and distort markets, resulting in limited agricultural investment and lower productivity. Consumers, acting as input procurement (including households and the buyers of food items), are also likely to suffer from food price volatilities, losing the ability to make optimal budget allocations. The recent protracted market volatilities of agricultural commodities in the regional markets of developing countries are largely attributable to external markets (Ceballos et al. 2017).

Self-sufficiency measures have attracted the attention of policymakers in developing regions such as Egypt, Senegal, India, the Philippines, Qatar, Bolivia and Russia as a potent strategy for national food security (Clapp 2017). Governments seek to increase self-sufficiency for several reasons, such as concerns about food supply disruption due to war, poor harvests in foreign countries and export restrictions; to avoid politically vulnerable positions in international negotiations; to conserve the natural environment and to grapple with concessions in agricultural industries. Nevertheless, economists who espouse modern economic theories are generally opposed to costly protectionist policies on the grounds that market interventions lead to inefficient resource allocations. Here, it is helpful to note that Magrini et al. (2017) argue that no consensus yet exists on the relationship between agricultural incentives and food security improvement (degradation). The food market turbulence of the 1970s caused governments to lean toward protectionist policies. Between the 1980s and 2000s, global agricultural prices were relatively low, and many African nations became net importers of food as a 
result of structural adjustment reforms advised by the International Monetary Fund or the World Bank which compelled governments to prioritize free-market policies. The present enthusiasm for food autarky policies re-emerged during the food crisis of 2007 -2008 and was complemented by the food sovereignty movement that began in the 1990s (Clapp 2017).

The research has not yet identified which factors may influence volatility passthroughs between world and local markets. Most studies focus on the links between the domestic markets of developing countries (Abdulai 2000; Baulch 1997; Lutz et al. 2006; Moser et al. 2009; Myers 2013); only a relatively small number of studies on domestic market linkages examine price transmission from world to local markets, including volatility transmission (Ceballos et al. 2017; Conforti 2004; Guillaume and Kaminski 2019; Minot 2011; Hatzenbuelhler et al. 2017; Mundlak and Larson 1992). Many of these works use an error-correction method to examine the relationship between global and domestic prices for specific countries. However, these studies fail to identify the determinants of the extent of the spillover effects in a comprehensive manner (i.e. through a panel analysis).

The qualitative research on food self-sufficiency is much more abundant than the quantitative research (Bishwajit 2014; Bishwajit et al. 2013; Clapp 2017; Warr 2011). While Tanaka and Hosoe (2011) and Tanaka (2018) quantify how rice and wheat selfsufficiency impact households in Japan and Egypt, respectively, they use a stochastic general equilibrium model, the parameters of which are often criticized for producing unreliable estimations (more specifically, this model generates a point estimation from a single-year social accounting matrix). Several studies have conducted quantitative analyses associated with self-sufficiency in food other than the CGE works explained above (Anderson and Tyres 1984; Yang and Tyers 1989), but these articles focus on assessing the impacts of a certain variable(s) on food self-sufficiency rather than the effects of food self-sufficiency on economies. Studies of the former type do not address the effectiveness of food autarky policy measures for national food security.

The present research extends Guo and Tanaka's (2019) work ${ }^{2}$ on wheat markets by exploring the determinants of grain (i.e. wheat, rice, maize) price volatility transmission from international markets to local markets with a two-step experimental procedure, namely, GARCH models with a dynamic conditional correlation (DCC) specification and panel feasible generalized least square (FGLS) models. The analysis considers data from January 2006 to December 2013 for 16 developing countries in Africa, Asia and Latin America in order to analyze food policies that reduced price transmission from global markets. ${ }^{3}$ We focus on the self-sufficiency rates (SSRs) of wheat, rice and maize to investigate the price transmission of the individual commodities and the consumption of substitutive goods (i.e. the substitutive consumption of rice and maize amid wheat price transmission). We hypothesize that consumers engage in substitution

\footnotetext{
${ }^{2}$ Guo and Tanaka (2019) analyze wheat price volatility transmissions from global to local markets in 10 wheat-importing countries, identifying the potential determinants with a panel analysis. They reveal that the volatility correlations from international to local markets were strengthened around the period of the 200708 food crisis and a higher self-sufficiency rate plays a role in alleviating volatility passthroughs from international markets.

${ }^{3}$ As sensitivity tests, we use extensive data comprising 16, 26 and 26 countries for wheat, rice and maize, respectively, and find that our main results are generally robust against changes in country selection (see the Appendix for details).
} 
behaviour during their grain consumption and that substitutive cereal consumption buffers price volatility transmission from global markets. We thus include the consumption of other cereals as explanatory variables in the identification process.

This study contributes to the literature in several ways. First, it makes a methodological contribution to international cereal volatility spillover research by applying the DCC framework to the volatility issue, which captures the time-variant correlated relationships between markets. By contrast, the conventional GARCH-BEKK method, as used by Ceballos et al. (2017), outputs a single coefficient value for each commodity, which would prevent us from regressing the correlation outcomes on potential factors due to the limited sample size. Second, this study is the first to conduct factor identification for the international volatility transmission of agricultural products within a rigorous econometric framework. Finally, despite the popularity and importance of food self-sufficiency policies, their effects on market steadiness have not been tested using econometric models.

The remainder of this paper proceeds as follows. The 'Methods' section describes the study's data, sample statistics and methodology. The 'Results and discussion' section outlines the empirical results. Finally, the 'Conclusions' section offers concluding remarks and several policy implications stemming from the findings.

\section{Methods}

\section{Data description}

In the first step, we used monthly data from the Global Information and Early Warning System (GIEWS), which provides monthly international food commodity prices in various countries to estimate the monthly conditional correlations between international and local markets for each cereal good. This dataset primarily covers developing markets at the city level. We selected a series of monthly local grain prices for individual countries in US dollars to deflate the domestic prices. Data on monthly local and international prices were collected for 16 countries from January 2006 to December 2013. The 16 countries selected differ between grains due to limited data availability. ${ }^{4}$ The data provided useful information on the following countries: for wheat, we considered Afghanistan, Argentina, Brazil, Cameroon, Ethiopia, Georgia, India, Israel, Kazakhstan, Kyrgyzstan, Mauritania, Peru, South Africa, Tajikistan, Ukraine and Uruguay; for rice, we considered Argentina, Brazil, El Salvador, Nicaragua, Panama, Peru, Cameroon, Ethiopia, Mozambique, Nigeria, Rwanda, South Africa, Zambia, Uganda, Israel and Ukraine and for maize, we considered Bangladesh, Brazil, Cambodia, Cameroon, Colombia, Salvador Guatemala, Haiti, India, Mauritania, Mozambique, Niger, Panama, Peru, South Africa and Uruguay. ${ }^{5}$ The international prices of wheat and maize are based on US (Gulf) no. 2 hard red winter wheat and US (Gulf) no. 2 yellow, respectively. International rice prices are based on Thailand 5\% milled white rice. Global prices are quoted from the GIEWS as well. Our country sample includes net grain exporters,

\footnotetext{
${ }^{4}$ Since yearly data is used in the panel analysis, the dimensions of the data set were chosen to include as many countries as possible to increase the sample size and degrees of freedom to yield more precise estimates. In the GIEWS, only 16 countries met the study's requirements for available data on the prices of wheat from 2006 to 2013. Although more data was available for rice and maize, the sample of countries differed for each grain (the countries selected for rice and maize were adjusted to be consistent with wheat prices).

${ }^{5}$ The Appendix details an identical estimation using a wider range of countries for rice and maize.
} 
such as Ukraine and Kazakhstan, with cereal self-sufficiency exceeding 100\% (the selfsufficiency standard is $100 \%$ ). We hypothesize that a country with high cereal selfsufficiency will tend to be resistant against violent fluctuations in international cereal prices. In addition, continuously compounded returns for each series are defined as $\ln \left(P_{t} / P_{t-1}\right) \times 100$, where $P_{t}$ is the monthly value of the global and local prices of wheat, maize and rice in a selected country.

Tables 1, 2 and 3 report the descriptive statistics of the returns on wheat prices (international and domestic markets), maize prices (international and domestic markets) and rice prices (international and domestic markets), respectively. These tables show that almost all mean returns are positive, suggesting an increase in grain prices during the study period. It is worth noting that the standard deviations of maize and rice prices reach levels higher than the standard deviation of wheat prices. This indicates that extreme changes tend to occur more frequently for maize and rice. The nonzero skewness and positive excess kurtosis of all the price returns exhibit a leptokurtic distribution (i.e. fat tails). Furthermore, the Jarque-Bera statistics reject normality at the $1 \%$ significance level for almost all price returns, indicating that most price returns depart from normal distribution.

Before estimating the dynamic correlations, it was necessary to verify the stationarity of each price return used in the analysis. The augmented Dickey and Fuller (1979; ADF) and Phillips and Perron (1988; PP) unit root test (which has a null hypothesis of a unit root) were employed to investigate whether the series of price returns was stationary. The results of the unit root tests indicated that all the variables are not stationary in their levels and none of the variables had unit root processes in their first logdifferenced forms. ${ }^{6}$ This suggests that all grain prices are stationary in their returns, guaranteeing that we can model volatility spillovers based on the GARCH with a DCC approach. ${ }^{7}$ It is vital to note that we lag the domestic price of each developing country by one period (i.e. by one month) to capture the information flowing from the global grain market to the local grain market with a time lag.

After estimating the monthly conditional correlations between international and local prices, ${ }^{8}$ we converted them into yearly data to conduct panel data analyses to identify the determinants of volatility transmission. ${ }^{9}$ Yearly consumption data for wheat, rice and maize and on the SSRs of individual grain products (i.e. the production and consumption of each nation) between 2006 and 2013 were retrieved from FAOSTAT. Table 4 defines the variables used in the panel estimation.

\section{Econometric methodology}

Our analysis employed a two-step econometric methodology. In the 'Dynamic conditional correlations' section, we use GARCH models within a DCC framework to define the linkages between the internal and external price volatilities of cereal markets in

\footnotetext{
${ }^{6}$ For sake of brevity, we do not report the results of the unit root tests here. They are available upon request.

${ }^{7} \mathrm{~A}$ number of researches have focused on the problem of testing for a unit root in the presence of volatility.

For instance, Cavaliere et al. (2015) suggest that standard lag selection methods show a tendency to over-fit the lag order under heteroskedasticity, which results in significant power losses in the ADF tests.

${ }^{8}$ It is vital to note that we lag the global price in the cereal market by one period (i.e. one month) to capture information flowing from global markets to local markets in developing countries with a time lag.

${ }^{9}$ David and Amir (2017) use the same method to obtain yearly DCCs by taking the average of the monthly DCCs.
} 
Table 1 Summary statistics for wheat price returns

\begin{tabular}{lllllllll}
\hline & Mean & Median & Maximum & Minimum & Std. dev. & Skewness & Kurtosis & Jarque-Bera \\
\hline $\begin{array}{l}\text { International wheat } \\
\text { price }\end{array}$ & 0.007 & -0.006 & 0.239 & -0.278 & 0.085 & 0.184 & 4.329 & $7.449^{\mathrm{a}}$ \\
Afghanistan & 0.006 & 0.000 & 0.515 & -0.229 & 0.088 & 1.924 & 14.602 & $585.233^{\mathrm{b}}$ \\
Argentina & 0.019 & 0.000 & 0.627 & -0.302 & 0.104 & 2.793 & 16.68 & $855.266^{\mathrm{b}}$ \\
Brazil & 0.006 & 0.008 & 0.128 & -0.241 & 0.059 & -0.874 & 5.517 & $36.778^{\mathrm{b}}$ \\
Cameroon & 0.003 & 0.000 & 0.216 & -0.227 & 0.053 & -0.162 & 9.043 & $143.457^{\mathrm{b}}$ \\
Ethiopia & 0.005 & 0.002 & 0.338 & -0.216 & 0.074 & 0.511 & 7.35 & $78.212^{\mathrm{b}}$ \\
Georgia & 0.006 & 0.000 & 0.118 & -0.168 & 0.046 & -0.404 & 5.252 & $22.419^{\mathrm{b}}$ \\
India & 0.002 & 0.000 & 0.161 & -0.144 & 0.048 & 0.154 & 4.839 & $13.622^{\mathrm{a}}$ \\
Israel & 0.008 & 0.008 & 0.109 & -0.108 & 0.037 & 0.223 & 4.173 & $6.174^{\mathrm{a}}$ \\
Kazakhstan & 0.005 & 0.000 & 0.182 & -0.185 & 0.040 & 0.404 & 12.599 & $363.438^{\mathrm{b}}$ \\
Kyrgyzstan & 0.006 & 0.000 & 0.405 & -0.123 & 0.068 & 2.613 & 14.988 & $669.883^{\mathrm{b}}$ \\
Mauritania & 0.004 & 0.000 & 0.139 & -0.217 & 0.039 & -0.788 & 16.351 & $707.839^{\mathrm{b}}$ \\
Peru & 0.005 & 0.000 & 0.078 & -0.035 & 0.017 & 0.904 & 5.902 & $45.785^{\mathrm{b}}$ \\
South Africa & 0.007 & 0.002 & 0.178 & -0.288 & 0.069 & -0.793 & 6.224 & $50.578^{\mathrm{b}}$ \\
Tajikistan & 0.007 & 0.000 & 0.281 & -0.141 & 0.053 & 1.249 & 10.02 & $217.443^{\mathrm{b}}$ \\
Ukraine & 0.006 & 0.009 & 0.152 & -0.269 & 0.054 & -1.38 & 10.969 & $278.556^{\mathrm{b}}$ \\
Uruguay & 0.009 & 0.014 & 0.274 & -0.227 & 0.067 & 0.151 & 7.984 & $97.636^{\mathrm{b}}$ \\
\hline
\end{tabular}

${ }^{\mathrm{a}}$ and $^{\mathrm{b}}$ indicate statistical significance at the $5 \%$ and $1 \%$ levels, respectively

Table 2 Summary statistics for maize price returns

\begin{tabular}{|c|c|c|c|c|c|c|c|c|}
\hline & Mean & Median & Maximum & Minimum & Std. dev. & Skewness & Kurtosis & Jarque-Bera \\
\hline $\begin{array}{l}\text { International maize } \\
\text { price }\end{array}$ & 0.007 & 0.004 & 0.210 & -0.236 & 0.075 & -0.164 & 4.176 & $5.841^{\mathrm{a}}$ \\
\hline Argentina & 0.008 & 0.004 & 0.277 & -0.228 & 0.079 & 0.582 & 5.366 & $27.228^{c}$ \\
\hline Brazil & 0.003 & 0.009 & 0.184 & -0.244 & 0.071 & -0.326 & 3.924 & $5.016^{\mathrm{a}}$ \\
\hline Cameroon & 0.01 & 0.016 & 0.314 & -0.147 & 0.06 & 1.728 & 12.007 & $364.521^{c}$ \\
\hline Ethiopia & 0.009 & 0.001 & 0.507 & -0.311 & 0.121 & 0.519 & 5.803 & $34.998^{c}$ \\
\hline Israel & 0.007 & 0.007 & 0.156 & -0.17 & 0.051 & -0.475 & 5.158 & $21.782^{c}$ \\
\hline Mozambique & $\begin{array}{l}- \\
0.001\end{array}$ & 0.000 & 0.182 & -0.375 & 0.094 & -0.928 & 5.988 & $48.465^{c}$ \\
\hline Nicaragua & 0.007 & 0.028 & 0.239 & -0.554 & 0.147 & -1.419 & 5.836 & $63.017^{c}$ \\
\hline Nigeria & 0.004 & 0.001 & 0.372 & -0.378 & 0.119 & -0.515 & 4.756 & $16.23^{c}$ \\
\hline Panama & 0.009 & 0.000 & 0.154 & -0.192 & 0.057 & -0.231 & 4.521 & $9.9^{c}$ \\
\hline Peru & 0.009 & 0.007 & 0.123 & -0.034 & 0.026 & 1.962 & 9.055 & $203.863^{c}$ \\
\hline Rwanda & 0.004 & 0.011 & 0.434 & -0.605 & 0.13 & -1.04 & 8.364 & $129.644^{c}$ \\
\hline Salvador & 0.004 & 0.000 & 0.214 & -0.147 & 0.064 & 0.451 & 4.786 & $15.687^{c}$ \\
\hline South Africa & 0.005 & 0.011 & 0.232 & -0.238 & 0.075 & -0.103 & 4.026 & 4.287 \\
\hline Uganda & 0.005 & 0.01 & 0.535 & -0.546 & 0.171 & -0.361 & 4.233 & $8.000^{b}$ \\
\hline Ukraine & 0.005 & 0.016 & 0.323 & -0.521 & 0.114 & -2.262 & 11.622 & $371.29^{c}$ \\
\hline Zambia & $\begin{array}{l}- \\
0.003\end{array}$ & 0.013 & 0.145 & -0.324 & 0.079 & -1.376 & 5.565 & $55.448^{c}$ \\
\hline
\end{tabular}

${ }^{\mathrm{a}}{ }^{\mathrm{b}}$ and ${ }^{\mathrm{c}}$ indicate statistical significance at the $10 \%, 5 \%$ and $1 \%$ levels, respectively 
Table 3 Summary statistics for rice price returns

\begin{tabular}{lllllllll}
\hline & Mean & Median & Maximum & Minimum & Std. dev. & Skewness & Kurtosis & Jarque-Bera \\
\hline International price & 0.005 & 0.000 & 0.412 & -0.190 & 0.076 & 2.425 & 14.387 & $599.983^{c}$ \\
Bangladesh & 0.005 & 0.102 & 0.522 & -0.605 & 0.333 & -0.234 & 1.601 & $8.517^{\mathrm{b}}$ \\
Brazil & 0.003 & -0.004 & 0.553 & -0.588 & 0.241 & -0.437 & 3.378 & 3.556 \\
Cambodia & 0.005 & 0.022 & 0.711 & -0.928 & 0.353 & -0.479 & 3.087 & 3.626 \\
Cameroon & 0.005 & 0.021 & 0.441 & -0.347 & 0.172 & 0.295 & 3.079 & 1.386 \\
Colombia & 0.006 & 0.069 & 0.576 & -0.864 & 0.326 & -1.268 & 4.296 & $31.747^{c}$ \\
Guatemala & 0.004 & 0.015 & 0.565 & -0.507 & 0.249 & -0.031 & 3.118 & 0.070 \\
Haiti & 0.007 & 0.070 & 0.805 & -1.224 & 0.450 & -1.008 & 4.357 & $23.121^{c}$ \\
India & 0.003 & 0.042 & 0.280 & -0.545 & 0.197 & -1.173 & 4.082 & $26.144^{c}$ \\
Mauritania & 0.002 & -0.019 & 0.606 & -0.425 & 0.224 & 0.133 & 2.624 & 0.832 \\
Mozambique & 0.006 & 0.016 & 0.465 & -0.602 & 0.245 & -0.698 & 3.601 & $9.050^{\mathrm{b}}$ \\
Nigeria & 0.003 & 0.050 & 0.500 & -0.466 & 0.232 & -0.334 & 2.256 & 3.916 \\
Panama & 0.006 & 0.027 & 0.357 & -0.452 & 0.169 & -1.226 & 4.752 & $35.581^{c}$ \\
Peru & 0.001 & 0.024 & 0.362 & -0.274 & 0.162 & 0.122 & 1.993 & 4.202 \\
Salvador & 0.004 & -0.012 & 0.675 & -0.411 & 0.277 & 0.61 & 2.877 & $5.886^{\mathrm{a}}$ \\
South Africa & 0.005 & -0.038 & 0.639 & -0.515 & 0.256 & 0.284 & 3.044 & 1.272 \\
Uruguay & 0.006 & 0.019 & 0.788 & -0.953 & 0.349 & -0.591 & 3.403 & $6.104^{\mathrm{b}}$ \\
\hline
\end{tabular}

${ }^{\mathrm{a}}{ }^{\mathrm{b}}$ and ${ }^{\mathrm{c}}$ indicate statistical significance at the $10 \%, 5 \%$ and $1 \%$ levels, respectively

each developing country selected. Then, in the 'Panel analysis with FGLS regression' section, we explore which factors may curb these linkages by employing a panel analysis.

\section{Dynamic conditional correlations}

The econometric framework of our analysis can be formulated as follows:

Table 4 Definitions of variables in panel analysis

\begin{tabular}{|c|c|c|}
\hline Variable & Definition & Source \\
\hline$D C C_{i, t w}$ & $\begin{array}{l}\text { Dynamic conditional correlation of wheat between international price and country } \\
\text { i's domestic price with one lag at time } t \text {. }\end{array}$ & $\begin{array}{l}\text { Estimated by } \\
\text { author }\end{array}$ \\
\hline$D C C_{i, t M}$ & $\begin{array}{l}\text { Dynamic conditional correlation of maize between international price and country } \\
\text { i's domestic price with one lag at time } t \text {. }\end{array}$ & $\begin{array}{l}\text { Estimated by } \\
\text { author }\end{array}$ \\
\hline$D C C_{i, t R}$ & $\begin{array}{l}\text { Dynamic conditional correlation of rice between international price and country i's } \\
\text { domestic price with one lag at time } t \text {. }\end{array}$ & $\begin{array}{l}\text { Estimated by } \\
\text { author }\end{array}$ \\
\hline$S S R_{i, t}^{W}$ & $\begin{array}{l}\text { Self-sufficiency rate is of wheat is defined as Production / (Production + Import - } \\
\text { Export) in country } i \text { at time } t \text {. }\end{array}$ & FAOSTAT \\
\hline$S S R_{i, t}^{M}$ & $\begin{array}{l}\text { Self-sufficiency rate of maize is defined as Production / (Production + Import - } \\
\text { Export) in country } i \text { at time } t \text {. }\end{array}$ & FAOSTAT \\
\hline$S S R_{i, t}^{R}$ & $\begin{array}{l}\text { Self-sufficiency rate of rice is defined as Production / (Production + Import - Export) } \\
\text { in country } i \text { at time } t \text {. }\end{array}$ & FAOSTAT \\
\hline$W C_{i, t}$ & $\begin{array}{l}\text { Consumption of wheat is defined as } \ln \left(\text { Consumption }{ }_{i, t} / \text { Consumption }_{i, t-1}\right) \times 100 \text { in } \\
\text { country } i \text { at time } t \text {. }\end{array}$ & FAOSTAT \\
\hline$M C_{i, t}$ & $\begin{array}{l}\text { Consumption of maize is defined as } \ln \left(\text { Consumption }{ }_{i, t} / \text { Consumption }_{i, t-1}\right) \times 100 \text { in } \\
\text { country } i \text { at time } t \text {. }\end{array}$ & FAOSTAT \\
\hline$R C_{i, t}$ & $\begin{array}{l}\text { Consumption of rice is defined as } \ln \left(\text { Consumption } n_{i, t} / \text { Consumption }_{i, t-1}\right) \times 100 \text { in } \\
\text { country } i \text { at time } t \text {. }\end{array}$ & FAOSTAT \\
\hline
\end{tabular}




$$
\left\{\begin{array}{l}
r_{t}=E\left(r_{t} \mid \Omega_{t-1}\right)+\varepsilon_{t} \\
\varepsilon_{t} \mid \Omega_{t-1} \sim N\left(0, H_{t}\right) \\
H_{t}=D_{t} R_{t} D_{t}
\end{array}\right.
$$

where $r_{t}=\left(r_{1, t}, r_{2, t}\right)^{\prime}$ is a $2 \times 1$ vector of returns, including the international price $r_{1}$, ${ }_{t}$ and one of the developing countries' domestic prices, $r_{2, t} . \Omega_{t-1}$ is the time $t-1$ information set. $\varepsilon_{t}=\left(\varepsilon_{1, t}, \varepsilon_{2, t}\right)^{\prime}$ is a $2 \times 1$ vector of the error term with conditional mean $E\left(\varepsilon_{i, t} \mid \Omega_{i, t-1}\right)=0$ and conditional variance $E\left(\varepsilon_{i, t}^{2} \mid \Omega_{i, t-1}\right)=h_{i, t}, i=1,2 . \varepsilon_{t}$ is assumed to follow a conditionally normal distribution. $H_{t}$ is a $2 \times 2$ conditional variance-covariance matrix. $D_{t}$ is the diagonal matrix containing the conditional standard deviations, in which the arrays are $D_{t}=\operatorname{diag}\left[\sqrt{h_{1, t}}, \sqrt{h_{2, t}}\right]$. The time-varying conditional correlation matrix $R_{t}$ is calculated as $R_{t}=\left[\operatorname{diag}\left(Q_{t}\right)^{-\frac{1}{2}}\right] Q_{t}\left[\operatorname{diag}\left(Q_{t}\right)^{-\frac{1}{2}}\right]$, where $Q_{t}$ is the conditional correlation matrix of the standardized residuals. Moreover, the matrix $H_{t}$ can be computed using the standardized residuals $z_{i, t}\left(z_{i, t}=\varepsilon_{i, t} / \sqrt{h_{i, t}}\right), i=1,2$. According to Glosten et al. (1993), the specification for the univariate GJR-GARCH $(1,1)$ model is as follows:

$$
h_{i, t}=\omega+\alpha_{i} \varepsilon_{i, t-1}^{2}+\lambda_{i} I_{i, t-1}^{-} \varepsilon_{i, t-1}^{2}+\beta_{i} h_{i, t-1}, \quad i=1,2
$$

where the indicator function $I_{i, t}^{-}$equals 1 if $\varepsilon_{i, t-1}<0$ and 0 otherwise. The parameter $\lambda_{i}$ is designed to capture the asymmetric effect. For this specification, a positive value for $\lambda_{i}$ indicates that negative residuals (bad news) tend to increase the variance more than positive residuals (good news). In other words, bad news $\left(\varepsilon_{i, t}-1<0\right)$ increases volatility more than good news $\left(\varepsilon_{i, t-1}>0\right)$. The univariate GJR-GARCH model described above is applied to estimate the time variances for each price return. Moreover, the standardized residuals obtained from the GJR-GARCH model were used to estimate the conditional cross-correlation. Cappiello et al. (2006) indicate that the shortcoming of the original DCC model is that the correlation evolves according to a process with identical news impacts and smoothing parameters for all pairs of variables. They also confirm that, for high dimensional models, the assumption of the identical impact of shocks is too strong. In response, they propose using an asymmetric generalized DCC (AG-DCC) model to better capture any heterogeneities present in the data. We follow Cappiello et al. (2006) and employ the AG-DCC model to account for both the time-varying correlation between variables and the asymmetric response of correlation to positive and negative shocks. The dynamic correlation structure of the AGDCC model is expressed as

$$
Q_{t}=\left(\bar{Z}-\phi^{\prime} \bar{Z} \phi-\xi^{\prime} \bar{Z} \xi-\eta^{\prime} \bar{P} \eta\right)+\phi^{\prime} z_{t-1} z_{t-1}^{\prime} \phi+\eta^{\prime} p_{t-1} p_{t-1} \eta^{\prime} \eta \xi^{\prime} Q_{t-1} \xi
$$

where matrix $\phi$ evaluates the impacts of the past standardized shocks to current dynamic conditional correlations, matrix $\xi$ indicates how lagged correlations affect current correlations and matrix $\eta$ justifies the presence of asymmetric responses to positive and negative shocks. $\bar{Z}$ represents the unconditional matrices of $z_{t}$ and $\bar{P}$ represents the unconditional matrices of $p_{t}=I_{\left[z_{t}<0\right] \odot z_{t}}$, where $I_{\left[z_{t}<0\right]}$ is an indicator function equal to 1 if $z_{t}<0$ and 0 otherwise and $\odot$ indicates a Hadamard product. Ding and Engle (2001) argue that a sufficient condition for $Q_{t}$ in Eq. 3 is positive definite for all possible realizations where the intercept, $\bar{Z}-\phi^{\prime} \bar{Z} \phi-\xi^{\prime} \bar{Z} \xi-\eta^{\prime} \bar{P} \eta$, is positive semi- 
definite. We follow the approach outlined in Hafner and Franses (2003) and replace the expression of the intercept with $\bar{Z}-a^{2} \bar{Z}-b^{2} \bar{Z}-g^{2} \bar{P}$, where $a, b$ and $g$ are vectors containing the diagonal elements of the matrices $\phi, \xi$ and $\eta$, respectively. In order to guarantee the positive definite of $Q_{t}$, it must hold that $a^{2}+b^{2}+\psi g^{2}<1$ where $\psi$ is the maximum eigenvalue of $\bar{Z}^{-1 / 2} \overline{P Z}^{-1 / 2}$. Similarly, the generalized DCC model (G-DCC) is a special case of the AG-DCC when $\eta=0$. Since the expectations of $\bar{Z}$ and $\bar{P}$ are not feasible, $\bar{Z}$ and $\bar{P}$ are replaced with sample analogues, $T^{-1} \sum_{t=1}^{T} z_{t} z_{t}{ }^{\prime}$ and $T^{-1} \sum_{t=1}^{T} p_{t} p_{t}{ }^{\prime}$, respectively. In addition, we specify the conditional correlation matrix as $\operatorname{diag}\left(Q_{t}\right)^{-\frac{1}{2}}$ $=\operatorname{diag}\left(\frac{1}{\sqrt{q_{11, t}}}, \frac{1}{\sqrt{q_{22, t}}}\right)$. Accordingly, the correlation coefficient $\rho_{12}$ at time $t$ can be defined as

$$
\rho_{12, t}=\frac{q_{12, t}}{\sqrt{q_{11, t} q_{22, t}}}
$$

The AG-DCC model is a generalization of the multivariate GARCH-DCC model of Engle (2002) used to capture the conditional asymmetries in correlation. ${ }^{10}$ We use the AG-DCC model to examine grain price spillover across different developing markets. To guarantee the robustness of our results, we used the generalized dynamic conditional correlation (G-DCC); we fit the best model specification based on the BayesianSchwarz information criterion (BIC).

Finally, we estimated the parameters of the AG-DCC and G-DCC model by the Gaussian quasi-maximum likelihood estimation (QMLE), ${ }^{11}$ assuming conditional multivariate normality with the BFGS ${ }^{12}$ optimization algorithm. Engle and Sheppard (2001) indicate that the quasi-maximum likelihood estimator is consistent and asymptotically normal.

\section{Panel analysis with FGLS regression}

In the next step, we investigated the factors influencing grain price volatility transmission from international to local markets in developing countries. To address data limitation problems, we constructed panel data and considered our group of selected developing countries as a whole. A pooled OLS (or fixed effects) model was used to estimate the parameters. Since our test results indicated the presence of heteroskedasticity, cross-sectional dependence and autocorrelation in the model, ${ }^{13}$ we used an FGLS regression to estimate our panel model. The advantage of the FGLS method is that it allows for heteroskedasticity or autocorrelation in the error term. We take the dynamic conditional correlation estimated in the 'Dynamic conditional correlations' section as the dependent variable for each grain. Following the specification in Table 4, we constructed the following panel regression model:

\footnotetext{
${ }^{10}$ See Cappiello et al. (2006) for an extensive analysis of these models' advantages.

${ }^{11}$ See Bollerslev and Wooldridge (1992).

${ }^{12}$ BFGS (Broyden, Fletcher, Goldfarb and Shanno) is a quasi-Newton optimization method that uses information about the gradient of the function at the current point to calculate the best direction in which to find a better point. All GARCH-DCC model estimations were done using WinRats Professional 10.0.

${ }^{13}$ To save space, we do not report the results of the modified Wald test for heteroskedasticity, Wooldridge's (2002) autocorrelation test or the LM test of cross-sectional independence. These results can be obtained from the authors upon request.
} 


$$
\begin{aligned}
& D C C_{i, t}^{W}=c^{W}+\kappa_{1} S S R_{i, t}^{W}+\kappa_{2} M C_{i, t}+\kappa_{3} R C_{i, t}+v_{i, t}^{W} \\
& D C C_{i, t}^{M}=c^{M}+\gamma_{1} S S R_{i, t}^{M}+\gamma_{2} W C_{i, t}+\gamma_{3} R C_{i, t}+v_{i . t}^{M} \\
& D C C_{i, t}^{R}=c^{R}+\phi_{1} S S R_{i, t}^{R}+\phi_{2} W C_{i, t}+\phi_{3} M C_{i, t}+v_{i, t}^{R}
\end{aligned}
$$

Here, $D C C$ is the dynamic conditional correlation. Since only yearly data were available for the self-sufficiency rates of developing countries, we used the average value of the monthly dynamic conditional correlations to produce annualized data. $c$ is the constant, and $v_{i, t}$ is the heteroskedastic error term. Parameters $\kappa, \gamma$ and $\phi$ measure the impacts of factors that may influence price volatility transmission. The estimation results of these parameters are reported in the next section. ${ }^{14}$

\section{Results and discussion}

\section{Volatility transmission between global and local grain markets}

In the first stage, we estimated the volatility parameter ${ }^{15}$ in Eq. 2 for each price return by applying the univariate GJR-GARCH model. The estimated results for wheat, maize and rice are presented in Tables 5, 6 and 7, respectively. We can observe that the significant levels of the variance term $\beta$ imply a high level of persistence. We also note that the asymmetric terms $\lambda$ are almost statistically significant at the $1 \%$ level, indicating the presence of the leverage effect (asymmetric effect) whereby negative shocks have a greater impact on future volatility levels than positive shocks of the same magnitude. The standardized residuals (volatility) obtained from the GJR-GARCH for wheat, maize and rice model are plotted in Figs. 2, 3 and 4, respectively.

In the second stage, we used the standardized residuals obtained from the first stage to estimate the G-DCC's and AG-DCC's intercept parameters in Eq. 3. Specifically, $\phi$ and $\xi$ are the parameter metrics for G-DCC, and $\eta$ is the asymmetric term contained in the AG-DCC model. ${ }^{16}$ The second-stage estimation allows us to proceed to the examination of the time-varying conditional correlations and volatility spillovers from international grain prices to domestic grain prices. We also use the Bayesian information criterion (BIC) to select the best-fitting models. Tables 5, 6 and 7 show that the BIC of the G-DCC model has a lower value than that of the AG-DCC model in all cases except for Mauritania's wheat prices. Hence, the G-DCC model is best suited for almost all of the countries, and the AG-DCC model is applied to estimate the dynamic correlations between the international wheat prices and Mauritania's domestic wheat prices.

In the final stage, we computed the time-varying correlation coefficients in Eq. 4 for each country by maximizing the integrated log likelihood functions. We plotted the results for wheat, maize and rice in Figs. 5, 6 and 7, respectively. The descriptive statistics of the conditional correlations for wheat, maize and rice are presented in Tables 8, 9 and 10, respectively. As Fig. 5 and Table 8 show, the conditional correlations all display considerable variability in our sample period and exhibit different patterns across different countries. For example, Peru's dynamic correlation coefficients are the most stable, with the lowest standard deviation (0.089). Meanwhile, Mauritania's dynamic

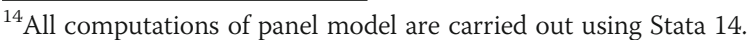

${ }^{15}$ The estimation results of the mean equation are omitted here but are available upon request.

${ }^{16}$ Given the multiplicity of local grain markets, the estimation results of the parameter metrics for the G-

DCC and AG-DCC models are available upon request.
} 
Table 5 Empirical results for wheat

\begin{tabular}{|c|c|c|c|c|c|}
\hline & \multicolumn{3}{|c|}{ Volatility parameters } & \multicolumn{2}{|c|}{ BIC criterion } \\
\hline & $\bar{a}$ & $\beta$ & $\lambda$ & AG-DCC & G-DCC \\
\hline International price & $-0.050^{d}$ & $1.063^{\mathrm{d}}$ & $-0.026^{d}$ & & \\
\hline Afghanistan & $0.640^{c}$ & $0.629^{d}$ & $-0.621^{c}$ & -365.105 & $-373.121^{a}$ \\
\hline Argentina & $0.756^{d}$ & $0.824^{d}$ & $-1.067^{d}$ & -343.323 & $-352.282^{a}$ \\
\hline Brazil & 0.185 & -0.017 & 0.423 & -419.735 & $-428,869$ \\
\hline Cameroon & $-0.009^{d}$ & $1.045^{\mathrm{d}}$ & $-0.120^{d}$ & -455.457 & $-462.306^{\mathrm{a}}$ \\
\hline Ethiopia & $0.299^{c}$ & $0.766^{d}$ & $-0.307^{c}$ & -375.085 & $-382.040^{a}$ \\
\hline Georgia & 0.290 & 0.312 & -0.271 & -454.611 & $-463,396^{a}$ \\
\hline India & $-0.114^{d}$ & $0.657^{d}$ & $-0.0003^{d}$ & -453.552 & $-460.023^{a}$ \\
\hline Israel & $0.315^{c}$ & $0.546^{d}$ & 0.111 & -518.176 & $-520.403^{a}$ \\
\hline Kazakhstan & $1.228^{d}$ & $-0.079^{d}$ & $1.315^{d}$ & -547.618 & $-556.808^{a}$ \\
\hline Kyrgyzstan & $0.025^{d}$ & $0.677^{d}$ & $-0.445^{d}$ & $-393,186$ & $-401.774^{a}$ \\
\hline Mauritania & $0.026^{d}$ & $1.025^{\mathrm{d}}$ & $-0.101^{d}$ & $-582.783^{a}$ & -581.487 \\
\hline Peru & $0.684^{c}$ & $0.504^{d}$ & -0.214 & -658.975 & $-664.758^{a}$ \\
\hline South Africa & -0.070 & 0.023 & $0.644^{c}$ & -395.570 & $-412.752^{a}$ \\
\hline Tajikistan & $1.343^{b}$ & 0.101 & -0.817 & -436.840 & $-442.670^{a}$ \\
\hline Ukraine & $-0.088^{d}$ & $-0.040^{b}$ & $0.721^{d}$ & -458.620 & $-467.778^{a}$ \\
\hline Uruguay & $-0.063^{d}$ & $0.632^{d}$ & $0.060^{d}$ & -396.943 & -406.008 \\
\hline
\end{tabular}

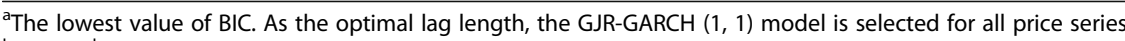

$b, c$ and ${ }^{d}$ indicate statistical significance at the $10 \%, 5 \%$ and $1 \%$ levels, respectively

correlation coefficients are the most volatile, with the highest standard deviation (0.276). Moreover, Fig. 5 broadly indicates that domestic wheat prices strongly correlate with international wheat prices and, moreover, that this relation fluctuates, that is, the prices demonstrate both positive and negative correlations. This result is different from that reported by Guo and Tanaka (2019): in their study, the correlation values between international and domestic wheat prices are almost positive. One possible explanation for both the positive and negative values of these dynamic correlations is that the speed of global-to-local price transmission may have varied during the sample period. For instance, Ethiopia's correlations were positive in mid-2007, suggesting that any increases or declines in the volatility of international wheat prices may intensify or decrease the volatility of domestic wheat prices. However, the correlations were negative during the 2007-2008 food crisis. Since we assume that information is transmitted from the global cereal market to a local cereal market with a one period lag, ${ }^{17}$ it is reasonable to wager that the price transmission from the international to the domestic market extended for more than one period during the food crisis. Further, as Table 8 makes clear, Mauritania has the highest average value (0.113) of dynamic correlation coefficients and, moreover, Uruguay's dynamic correlations are all negative and display the lowest average value $(-0.238)$. It is also interesting to note that the dynamic correlations of some countries (e.g. Argentina, Brazil, South Africa, Uruguay) fluctuated dramatically during the 2008 global financial crisis.

\footnotetext{
${ }^{17}$ The estimated DCC series in Figs. 5, 6 and 7 provided the time-varying correlations between local market price changes of current month and global market price changes of previous month.
} 
Table 6 Empirical results for maize

\begin{tabular}{|c|c|c|c|c|c|}
\hline & \multicolumn{3}{|c|}{ Volatility parameters } & \multicolumn{2}{|c|}{ BIC criterion } \\
\hline & $\bar{a}$ & $\beta$ & $\lambda$ & AG-DCC & G-DCC \\
\hline International price & $-0.150^{d}$ & $1.064^{\mathrm{d}}$ & $0.030^{d}$ & & \\
\hline Argentina & -0.085 & 0.656 & 0.234 & -402.954 & $-405.158^{a}$ \\
\hline Brazil & 0.349 & 0.133 & 0.228 & -426.321 & $-433.002^{a}$ \\
\hline Cameroon & $-0.071^{d}$ & $1.068^{\mathrm{d}}$ & $-0.154^{d}$ & -455.892 & $-463.972^{a}$ \\
\hline Ethiopia & 0.262 & $0.424^{c}$ & 0.368 & -319.245 & $-323.928^{a}$ \\
\hline Israel & 0.043 & $0.427^{c}$ & 0.332 & -499.594 & $-509.253^{a}$ \\
\hline Mozambique & 0.363 & $0.362^{c}$ & 0.140 & -388.027 & $-393.337^{a}$ \\
\hline Nicaragua & 0.303 & $0.922^{d}$ & $-0.365^{b}$ & -273.952 & $-281.632^{a}$ \\
\hline Nigeria & $-0.077^{d}$ & $1.057^{d}$ & $-0.067^{d}$ & -321.374 & $-330.102^{a}$ \\
\hline Panama & $-0.006^{d}$ & $1.050^{d}$ & $-0.145^{d}$ & -465.026 & $-473.103^{a}$ \\
\hline Peru & $1.661^{c}$ & 0.015 & $-1.693^{c}$ & -613.493 & $-617.421^{a}$ \\
\hline Rwanda & $-0.079^{d}$ & $1.054^{d}$ & $-0.023^{c}$ & -306.454 & $-316.819^{a}$ \\
\hline Salvador & $0.562^{d}$ & $0.583^{d}$ & $-0.653^{d}$ & -442.695 & $-451.760^{a}$ \\
\hline South Africa & $-0.118^{d}$ & $1.057^{\mathrm{d}}$ & $0.008^{d}$ & -402.535 & $-409.473^{a}$ \\
\hline Uganda & $-0.092^{d}$ & $0.694^{d}$ & $-0.064^{d}$ & -234.824 & $-240.093^{a}$ \\
\hline Ukraine & -0.036 & 0.085 & $3.191^{c}$ & -388.850 & $-395.461^{a}$ \\
\hline Zambia & $-0.198^{d}$ & $-0.232^{d}$ & $0.777^{d}$ & -406.124 & $-416.187^{a}$ \\
\hline
\end{tabular}

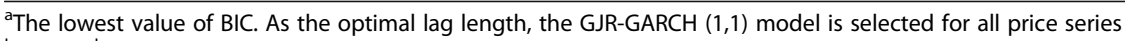
$b, c$ and ${ }^{d}$ indicate statistical significance at the $10 \%, 5 \%$ and $1 \%$ levels, respectively

Table 7 Estimation results for rice

\begin{tabular}{|c|c|c|c|c|c|}
\hline & \multicolumn{3}{|c|}{ Volatility parameters } & \multicolumn{2}{|c|}{ BIC criterion } \\
\hline & $\bar{a}$ & $\beta$ & $\lambda$ & AG-DCC & G-DCC \\
\hline International price & $0.688^{c}$ & $0.516^{c}$ & $-0.414^{c}$ & & \\
\hline Bangladesh & $2.085^{c}$ & $0.214^{c}$ & $-2.315^{c}$ & -192.905 & $-198.940^{\circ}$ \\
\hline Brazil & -0.076 & $0.767^{c}$ & 0.041 & -242.129 & -247.654 \\
\hline Cambodia & -0.117 & $0.788^{c}$ & 0.166 & -173.528 & $-181.743^{\circ}$ \\
\hline Cameroon & $-0.174^{c}$ & $0.728^{c}$ & $0.575^{c}$ & -319.429 & $-328.466^{\circ}$ \\
\hline Colombia & $-0.195^{b}$ & $0.745^{c}$ & 0.101 & -182.443 & $-189.825^{\circ}$ \\
\hline Guatemala & $-0.161^{c}$ & $1.052^{c_{-}}$ & $0.333^{c}$ & -242.224 & $-244.561^{a}$ \\
\hline Haiti & $-0.869^{c}$ & $0.857^{c}$ & $1.309^{c}$ & -143.635 & -151.554 \\
\hline India & $-0.475^{c}$ & $0.601^{c}$ & $0.516^{c}$ & -298.319 & $-307.384^{a}$ \\
\hline Mauritania & $0.328^{c}$ & $0.858^{c}$ & $-0.670^{c}$ & -272.869 & $-282.281^{\circ}$ \\
\hline Mozambique & $-0.362^{c}$ & $0.635^{c}$ & $0.116^{c}$ & -257.795 & $-267.315^{a}$ \\
\hline Nigeria & $-0.260^{c}$ & $-0.452^{c}$ & $0.062^{c}$ & -271.459 & -278.909 \\
\hline Panama & $-0.256^{c}$ & $0.6865^{c}$ & $0.0731^{c}$ & -338.044 & $-343.263^{\circ}$ \\
\hline Peru & $-0.278^{c}$ & $1.043^{c}$ & $0.415^{c}$ & -328.766 & $-335.351^{2}$ \\
\hline Salvador & $-0.243^{b}$ & $0.900^{c}$ & -0.190 & -227.105 & $-233.097^{\mathrm{a}}$ \\
\hline South Africa & $-0.224^{c}$ & $0.787^{c}$ & $0.623^{c}$ & -261.193 & -261.194 \\
\hline Uruguay & $-0.285^{c}$ & $1.051^{b}$ & $0.043^{c}$ & -179.948 & -188.233 \\
\hline
\end{tabular}

${ }^{a}$ The lowest value of BIC. As the optimal lag length, the GJR-GARCH $(1,1)$ model is selected for all price series

${ }^{b}$ and ${ }^{c}$ indicate statistical significance at the $5 \%$ and $1 \%$ levels, respectively 


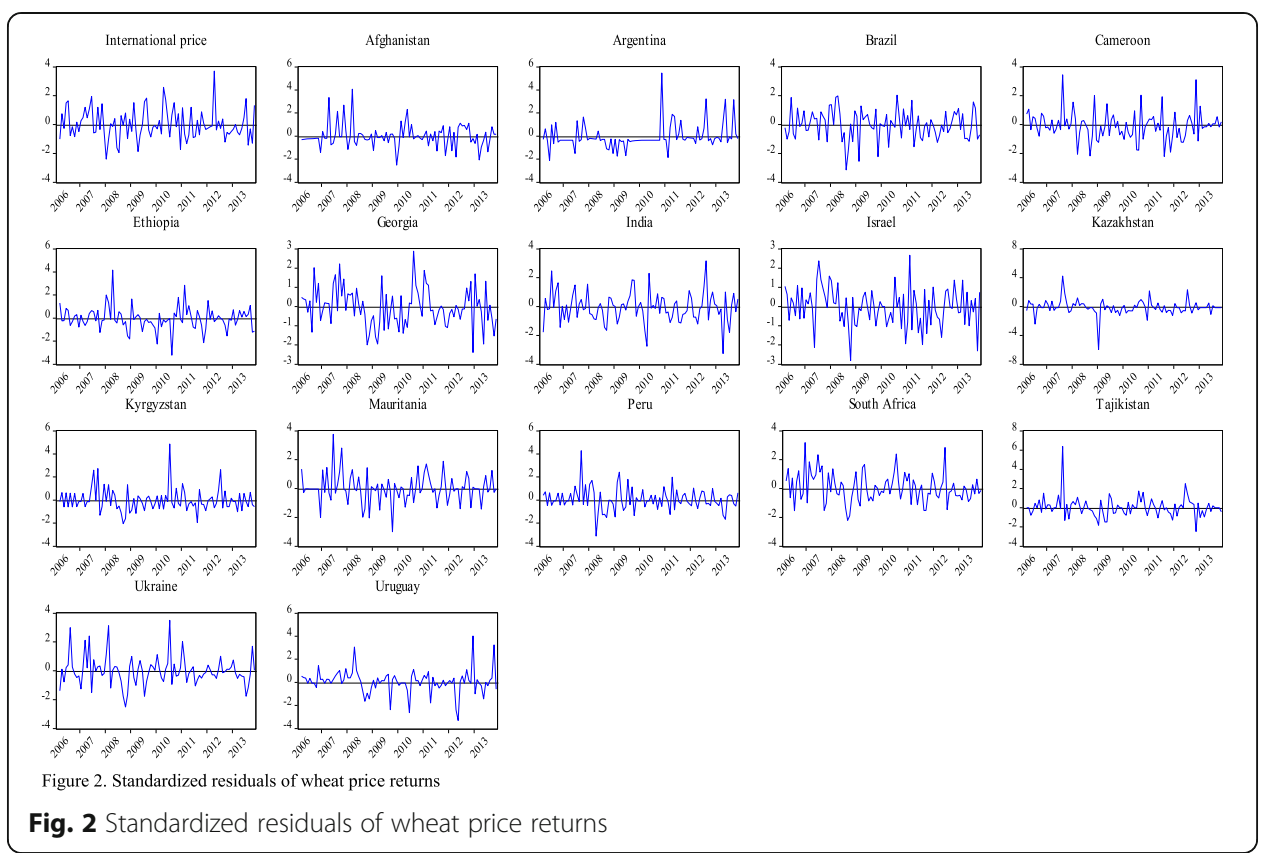

Figure 6 and Table 9 present the patterns and magnitudes of the correlations between international and domestic maize prices for all countries in the sample. Overall, a high variability is evident in the dynamic correlations of all countries. Notably, Rwanda's correlation coefficients fluctuated the most and thus had the highest standard deviation (0.253). Meanwhile, Ukraine's correlation coefficients were the most stable and thus had the lowest standard deviation (0.076). Figure 6 confirms that the dynamic correlations of Brazil, Israel and Ukraine were positive throughout the entire sample period. Also helpful to note is that the correlations between the international and domestic maize prices of Brazil and Ukraine exhibit inverse relationships to those of wheat. In addition, Table 10 shows that Israel has the highest (0.537) and Zambia the lowest (-0.100) average value among the dynamic correlation coefficients. Furthermore, we again notice that the

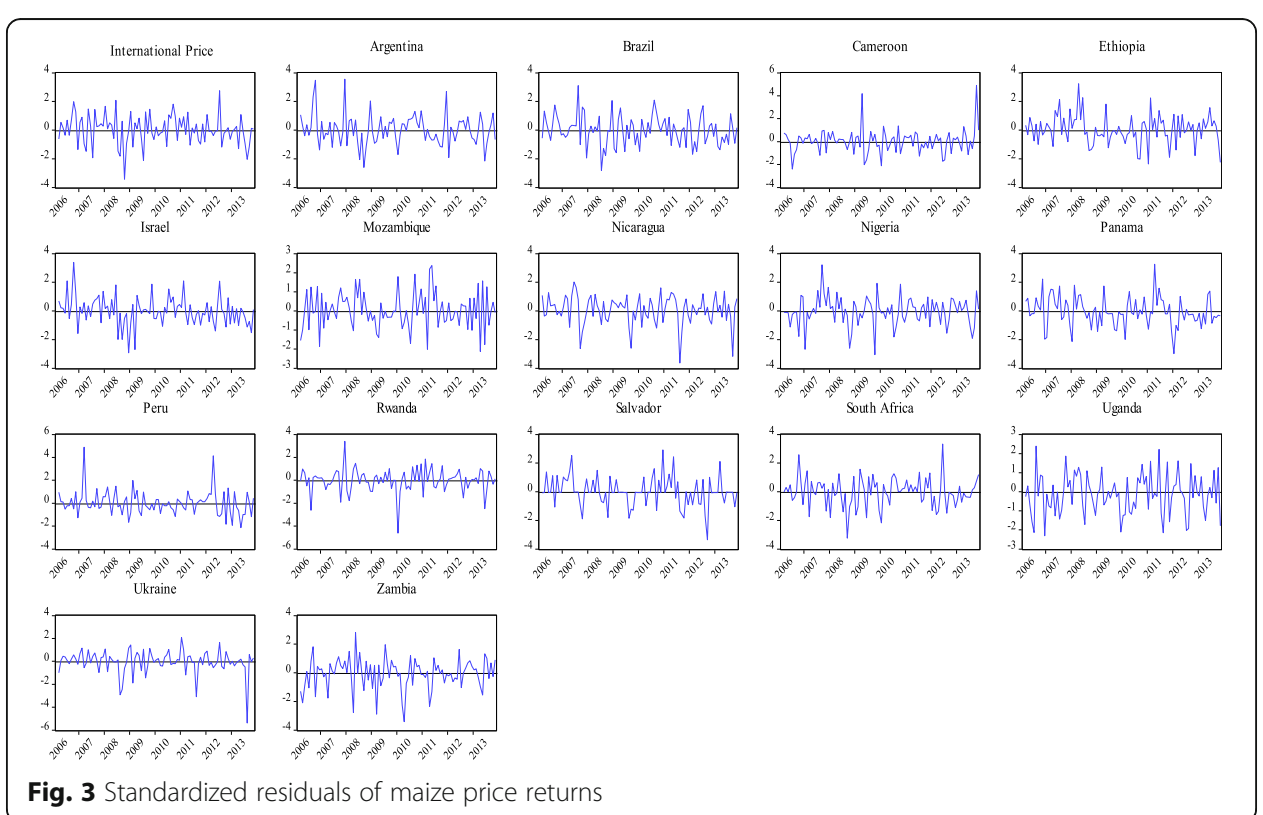




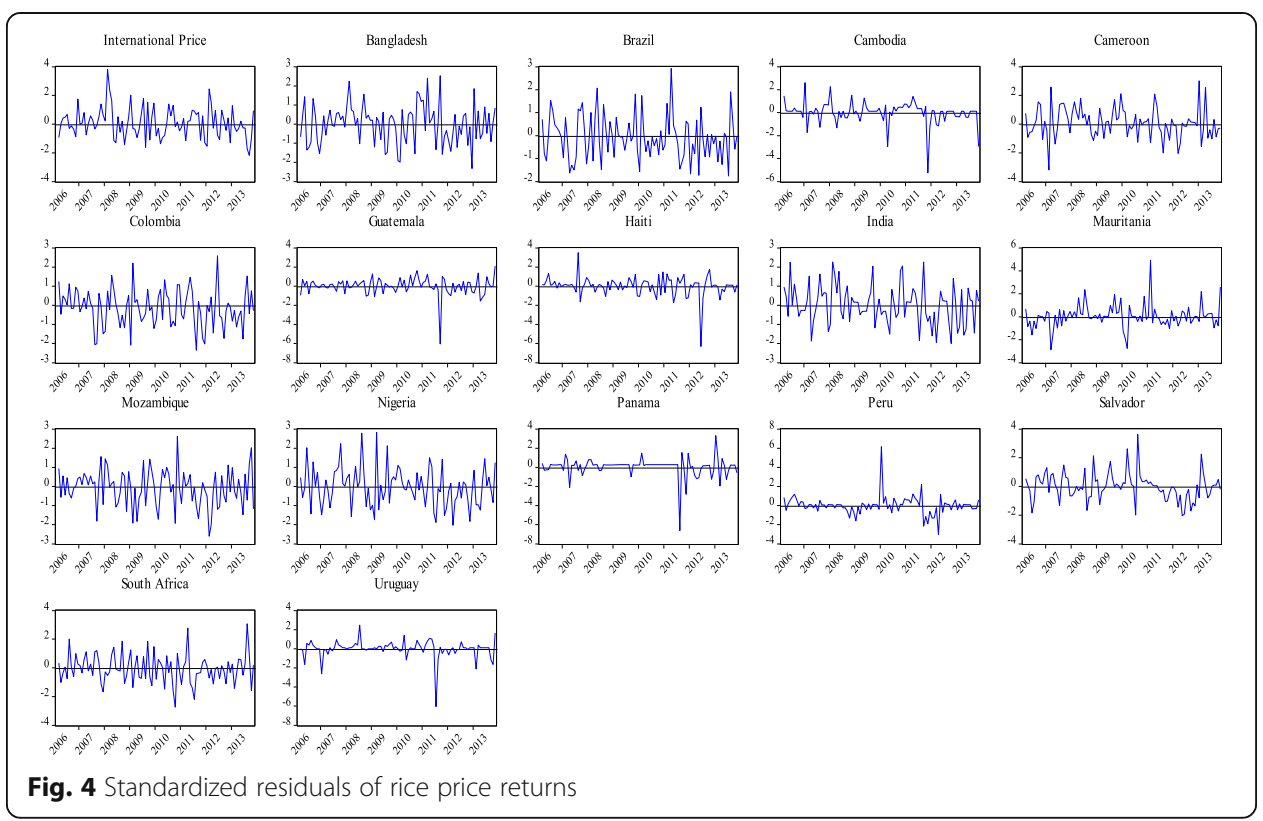

correlations for some countries (e.g. Mozambique, Nigeria, Panama, Peru) fluctuated significantly during the 2008 global financial crisis.

Finally, we examine the results for rice presented in Fig. 7 and Table 10. Consistent with the findings above, we observe generally high variability in the correlations between international and domestic rice prices in developing countries. Almost all of the conditional correlation coefficients (except for those of Haiti) fluctuated between positive and negative correlations. Table 10 shows that Cambodia's correlation coefficients have the highest (0.352) and Haiti's the lowest (0.024) standard deviations. Furthermore, the highest average dynamic correlation coefficient value is observed in

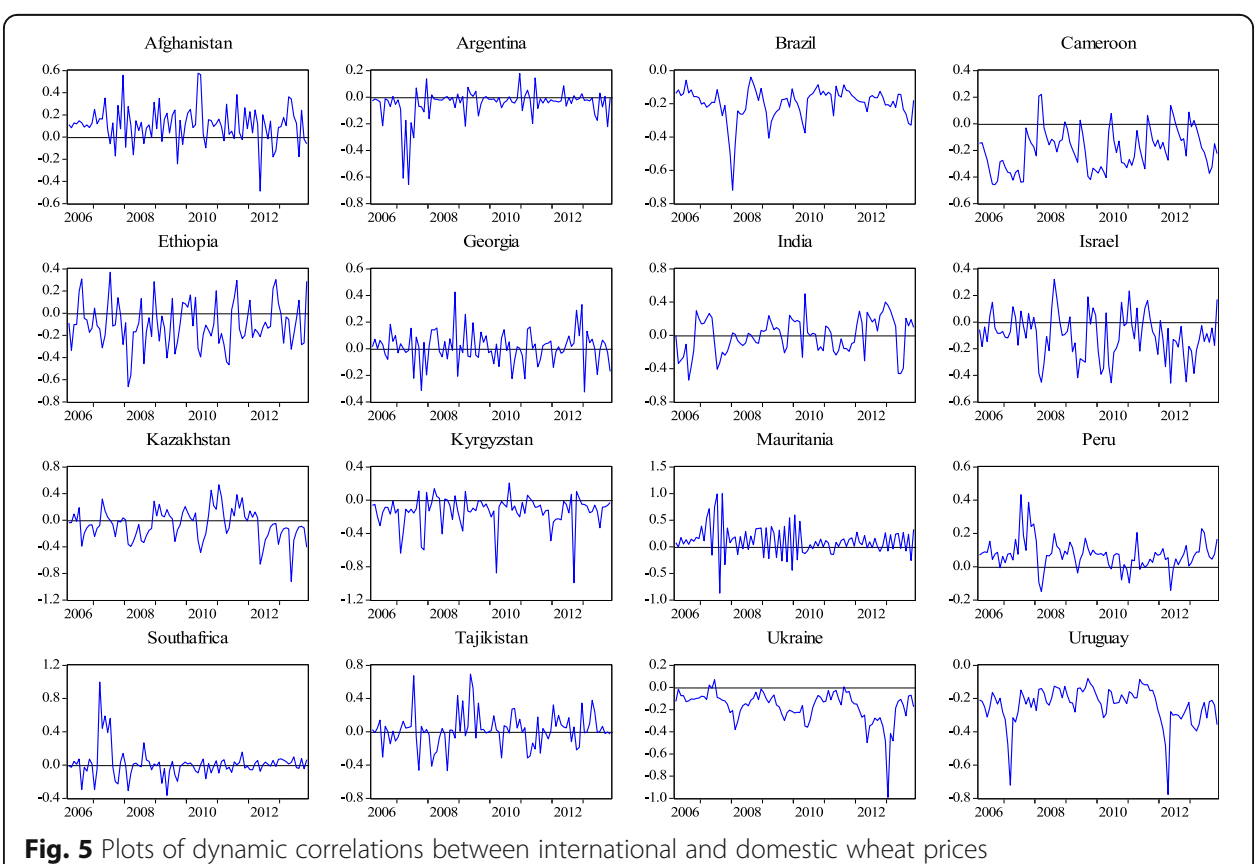

Fig. 5 Plots of dynamic correlations between international and domestic wheat prices 


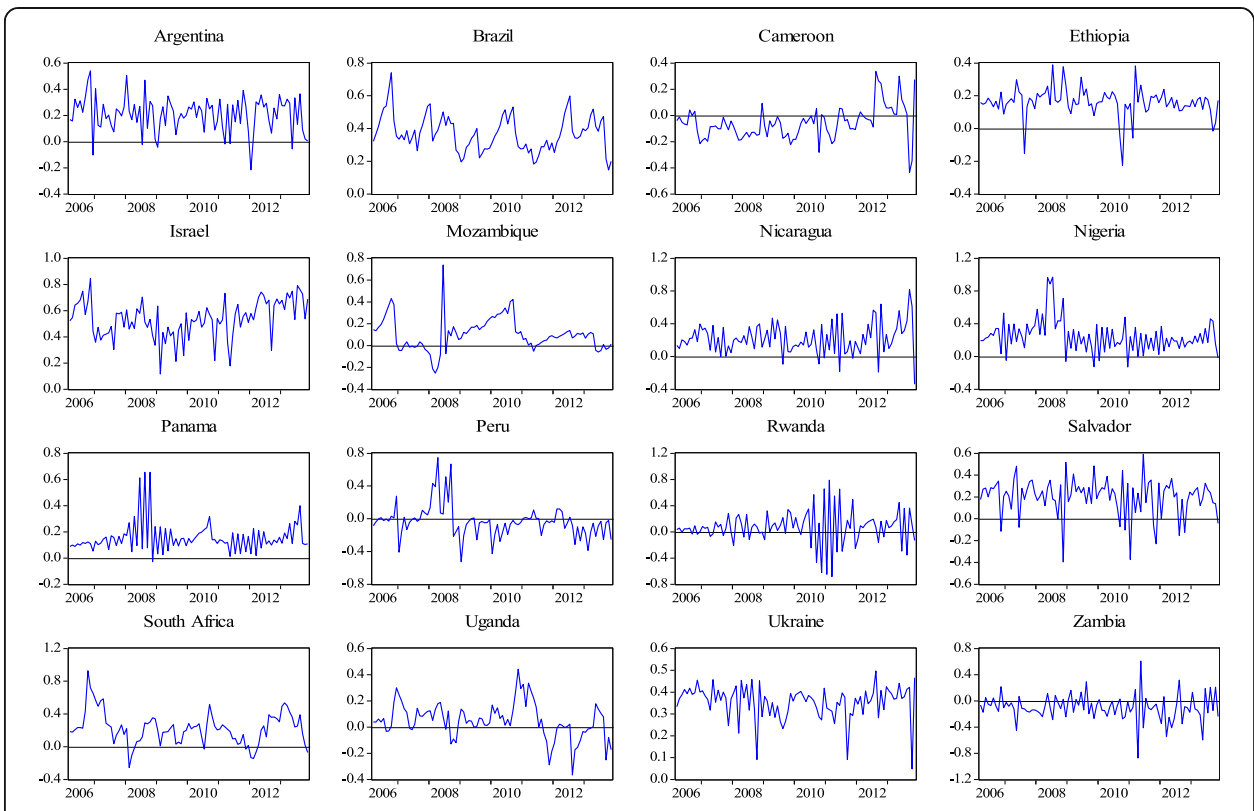

Fig. 6 Plots of dynamic correlations between international and domestic maize prices

Cameroon (0.208) and the lowest in Guatemala (-0.046). Additionally, some countries, such as Cameroon and Mozambique, display remarkable fluctuations during the 2008 global financial crisis.

\section{Identification of potential factors}

In this subsection, we estimate Eqs. 5, 6 and 7 to determine which factors might influence the time-varying conditional correlations identified above. Table 11 summarizes

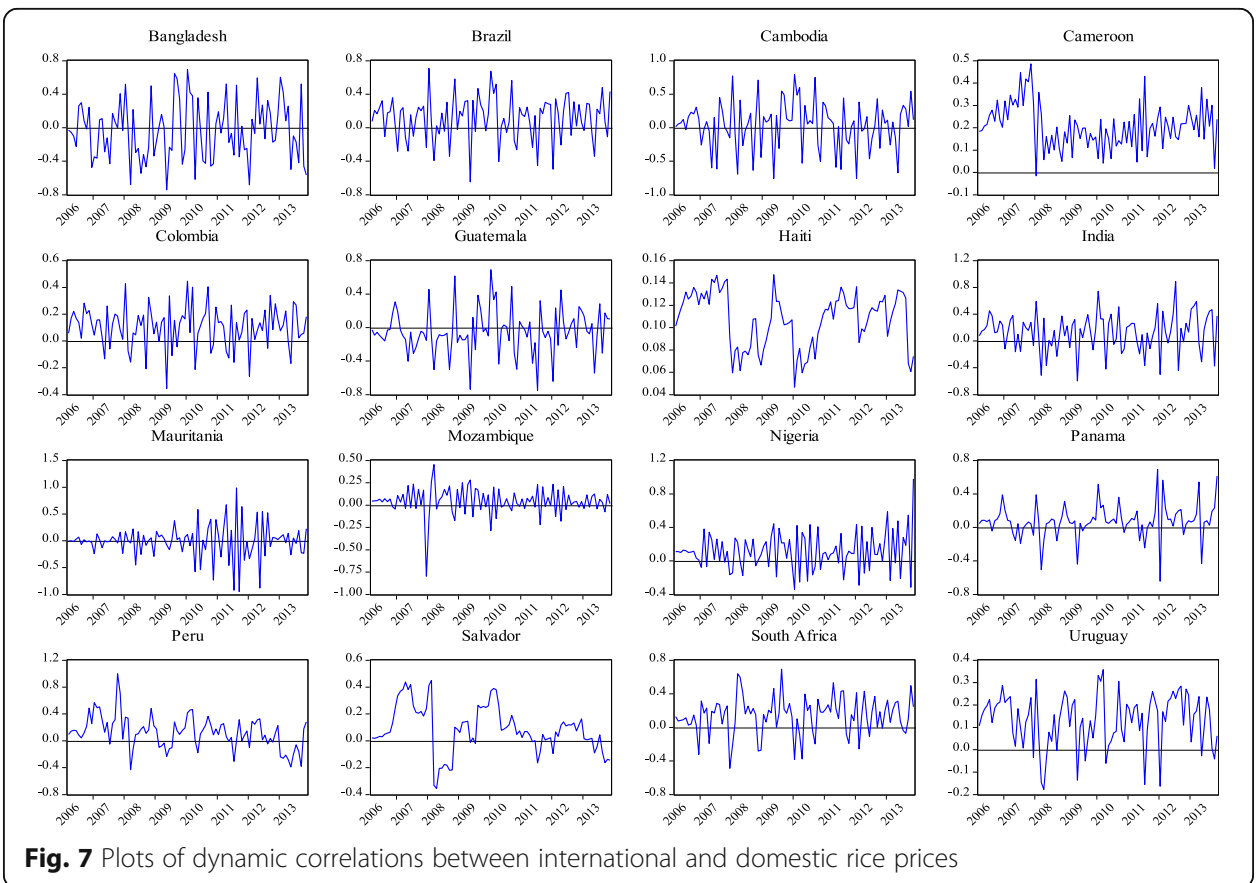


Table 8 Summary statistics for the dynamic conditional correlations of wheat

\begin{tabular}{llllll}
\hline & Mean & Median & Maximum & Minimum & Std. dev. \\
\hline Afghanistan & 0.112 & 0.111 & 0.576 & -0.488 & 0.164 \\
Argentina & -0.048 & -0.022 & 0.178 & -0.656 & 0.116 \\
Brazil & -0.196 & -0.174 & -0.040 & -0.720 & 0.097 \\
Cameroon & -0.192 & -0.193 & 0.220 & -0.457 & 0.155 \\
Ethiopia & -0.099 & -0.115 & 0.370 & -0.663 & 0.201 \\
Georgia & 0.011 & 0.015 & 0.426 & -0.326 & 0.125 \\
India & -0.003 & 0.025 & 0.498 & -0.538 & 0.214 \\
Israel & -0.101 & -0.094 & 0.321 & -0.460 & 0.168 \\
Kazakhstan & -0.061 & -0.059 & 0.533 & -0.921 & 0.236 \\
Kyrgyzstan & -0.131 & -0.096 & 0.206 & -0.994 & 0.190 \\
Mauritania & 0.113 & 0.099 & 0.997 & -0.873 & 0.276 \\
Peru & 0.074 & 0.074 & 0.432 & -0.150 & 0.089 \\
South Africa & 0.014 & 0.004 & 1.000 & -0.364 & 0.178 \\
Tajikistan & 0.025 & 0.018 & 0.693 & -0.469 & 0.205 \\
Ukraine & -0.172 & -0.131 & 0.070 & -0.991 & 0.143 \\
Uruguay & -0.238 & -0.223 & -0.079 & -0.777 & 0.112 \\
\hline
\end{tabular}

the results of a panel regression based on the FGLS model. It provides several interesting empirical findings. First, the coefficients of SSR are negative and significant at the $1 \%$ level for all three grains. These findings confirm that SSR can be considered a significant factor in determining dynamic correlations. Furthermore, the negative coefficient of SRR on DCC implies that an increase in SSR reduces the correlation between international and domestic grain prices. In other words, the governments of developing countries can lessen the impacts of unexpected excess volatility from global to local markets by adopting practices that increase their grain self-sufficiency rates. However, it is important to note that this finding cannot be simply applied to countries with domestic yield variability greater than import supply variability: higher self-sufficiency means higher dependency on domestic production, which, accordingly, makes domestic production more influential to domestic price. Therefore, the outcome obtained in our estimation needs to be interpreted as that a self-sufficiency policy tends to placate local price volatility from the collective observation of the 16 countries focused, but is not necessarily applicable to any individual nation. As a matter of fact, Tanaka and Hosoe (2011) demonstrate that the abolition of import tax on rice to Japan stabilizes the domestic price of rice-because Japan's rice productivity is more volatile than the international rice supply to Japan, cutting import taxes on rice increases the nation's rice imports. Along these lines, we found that the coefficient of maize's SSR has the largest negative value $(-0.054)$, while the coefficient of wheat's SSR is relatively small (0.006). These results suggest that maize's self-sufficiency rate has the greatest impact on maize's global and local price transmission in developing countries. Second, the coefficient of maize's consumption is significant at the $5 \%$ level in the regression for wheat. The coefficient is approximately -0.05 , which suggests that, on average, an increase in maize consumption will reduce the dynamic correlations between international and domestic wheat prices. It is also worth noting that the magnitude of maize consumption is larger than that of wheat's SSR, indicating that an increase in maize 
Table 9 Summary statistics for the dynamic conditional correlations of maize

\begin{tabular}{llllll}
\hline & Mean & Median & Maximum & Minimum & Std. dev. \\
\hline Argentina & 0.210 & 0.233 & 0.540 & -0.216 & 0.134 \\
Brazil & 0.371 & 0.360 & 0.740 & 0.147 & 0.109 \\
Cameroon & -0.059 & -0.065 & 0.336 & -0.435 & 0.126 \\
Ethiopia & 0.161 & 0.162 & 0.388 & -0.224 & 0.088 \\
Israel & 0.537 & 0.535 & 0.844 & 0.117 & 0.144 \\
Mozambique & 0.103 & 0.091 & 0.739 & -0.253 & 0.149 \\
Nicaragua & 0.217 & 0.198 & 0.816 & -0.339 & 0.190 \\
Nigeria & 0.249 & 0.235 & 0.968 & -0.129 & 0.200 \\
Panama & 0.154 & 0.131 & 0.655 & -0.028 & 0.115 \\
Peru & -0.035 & -0.040 & 0.746 & -0.525 & 0.194 \\
Rwanda & 0.069 & 0.070 & 0.789 & -0.684 & 0.253 \\
Salvador & 0.202 & 0.238 & 0.591 & -0.396 & 0.172 \\
South Africa & 0.226 & 0.221 & 0.929 & -0.256 & 0.195 \\
Uganda & 0.051 & 0.044 & 0.442 & -0.366 & 0.135 \\
Ukraine & 0.356 & 0.372 & 0.497 & 0.048 & 0.076 \\
Zambia & -0.100 & -0.107 & 0.606 & -0.873 & 0.198 \\
\hline
\end{tabular}

consumption impacts wheat's DCC more than an increase in wheat's SSR. Third, and most interestingly, our results indicate that the coefficient of wheat's consumption also negatively affects maize's DCC at a statistical significance level of $5 \%$. Moreover, the magnitude of the coefficient is -0.104 , which is approximately twice as large as the coefficient of maize's SSR. In other words, an increase in wheat consumption plays a greater role in buffering price volatility transmissions from global to local maize markets than an increase in maize's SSR. These results reveal a substitutive effect between maize and wheat and imply that increasing wheat (maize) consumption could be used

Table 10 Summary statistics for the dynamic conditional correlations of rice

\begin{tabular}{llllll}
\hline & Mean & Median & Maximum & Minimum & Std. dev. \\
\hline Bangladesh & -0.032 & -0.035 & 0.693 & -0.743 & 0.349 \\
Brazil & 0.116 & 0.166 & 0.710 & -0.646 & 0.260 \\
Cambodia & 0.040 & 0.085 & 0.791 & -0.758 & 0.352 \\
Cameroon & 0.208 & 0.208 & 0.486 & -0.016 & 0.100 \\
Colombia & 0.106 & 0.132 & 0.447 & -0.353 & 0.153 \\
Guatemala & -0.046 & -0.065 & 0.689 & -0.749 & 0.266 \\
Haiti & 0.107 & 0.113 & 0.147 & 0.047 & 0.024 \\
India & 0.135 & 0.157 & 0.887 & -0.596 & 0.281 \\
Mauritania & -0.006 & 0.020 & 0.988 & -0.947 & 0.316 \\
Mozambique & 0.043 & 0.043 & 0.452 & -0.795 & 0.151 \\
Nigeria & 0.118 & 0.103 & 0.979 & -0.340 & 0.227 \\
Panama & 0.076 & 0.069 & 0.693 & -0.643 & 0.204 \\
Peru & 0.125 & 0.128 & 0.999 & -0.432 & 0.240 \\
Salvador & 0.086 & 0.069 & 0.449 & -0.356 & 0.173 \\
South Africa & 0.141 & 0.170 & 0.693 & -0.489 & 0.223 \\
Uruguay & 0.133 & 0.156 & 0.358 & -0.178 & 0.118 \\
\hline
\end{tabular}


Table 11 Estimation results of panel data analysis

\begin{tabular}{|c|c|c|c|}
\hline \multirow{2}{*}{$\begin{array}{l}\text { Dependent } \\
\text { variable }\end{array}$} & \multicolumn{3}{|c|}{ Independent variable } \\
\hline & $D C C^{W}$ & $D C C^{M}$ & $D C C^{R}$ \\
\hline \multirow[t]{2}{*}{ SSR } & $-0.006^{b}$ & $-0.054^{b}$ & $-0.013^{b}$ \\
\hline & $(-5.91)$ & $(-7.41)$ & $(-0.72)$ \\
\hline \multirow[t]{2}{*}{$W C$} & - & $-0.104^{a}$ & 0.069 \\
\hline & - & $(-2.58)$ & $(1.39)$ \\
\hline \multirow[t]{2}{*}{ MC } & $-0.05^{\mathrm{a}}$ & - & -0.022 \\
\hline & $(-2.14)$ & - & $(-0.72)$ \\
\hline \multirow[t]{2}{*}{$R C$} & 0.014 & 0.039 & - \\
\hline & $(0.47)$ & $(0.55)$ & - \\
\hline \multirow[t]{2}{*}{ Constant } & $-0.065^{b}$ & $0.148^{\mathrm{b}}$ & $0.082^{b}$ \\
\hline & $(-11.06)$ & $(16.02)$ & $(9.43)$ \\
\hline Observations & 128 & 128 & 128 \\
\hline
\end{tabular}

${ }^{\mathrm{a}}$ and ${ }^{\mathrm{b}}$ indicate statistical significance at the $5 \%$ and $1 \%$ levels, respectively. $z$-statistics are in parentheses

as a strategy to buffer countries from excessive fluctuations in international maize (wheat) prices. Finally, contrary to the results for wheat and maize, the coefficients of the consumption of wheat and maize are insignificant in the regression model for rice. This may be due to a weak substitutive relationship between rice, wheat and maize.

\section{Conclusions}

This study sought to identify the factors determining the degree of price volatility transmission between the international and local markets of wheat, rice and maize in developing countries. In the first step, a GARCH model with AG-DCC and G-DCC specifications was developed to estimate the strength of the price volatility links between the global and regional cereal markets. In the second step, we regressed the correlated outcomes obtained in the first step on potential factors such as self-sufficiency in grain and the consumption of substitutive commodities. Our main findings were as

Table 12 Estimation results of panel data analysis with full-country selection

\begin{tabular}{llll}
\hline $\begin{array}{l}\text { Dependent } \\
\text { variable }\end{array}$ & \multicolumn{2}{l}{ Independent variable } & $\boldsymbol{D C C}^{\boldsymbol{R}}$ \\
\cline { 2 - 4 } & $\boldsymbol{D C C ^ { \boldsymbol { W } }}$ & $\boldsymbol{D C C ^ { \boldsymbol { M } }}$ & -0.002 \\
$\mathrm{SSR}$ & $-0.006^{\mathrm{b}}$ & $-0.021^{\mathrm{b}}$ & $(-1.13)$ \\
WC & $(-5.91)$ & $(-6.14)$ & 0.029 \\
& - & $-0.129^{\mathrm{a}}$ & $(0.576)$ \\
$M C$ & - & $(-2.93)$ & 0.050 \\
& $-0.05^{\mathrm{a}}$ & - & $(1.29)$ \\
$R C$ & $(-2.14)$ & - & - \\
& 0.014 & $-0.126^{\mathrm{b}}$ & - \\
Constant & $(0.47)$ & $(-3.33)$ & $0.090^{\mathrm{b}}$ \\
& $-0.065^{\mathrm{b}}$ & $0.171^{\mathrm{b}}$ & $(4.48)$ \\
Observations & $(-11.06)$ & $(14.29)$ & 208 \\
\hline
\end{tabular}

${ }^{\mathrm{a}}$ and ${ }^{\mathrm{b}}$ indicate statistical significance at the $5 \%$ and $1 \%$ levels, respectively. $z$-statistics in parentheses 
follows: (1) self-sufficiency policies for grain commodities can reduce volatility passthroughs from global markets; (2) the consumption of wheat and maize as substitutive goods can buffer the price volatility transmissions of maize and wheat, respectively; however, these substitutive effects many not occur in rice markets and (3) grain substitution impacts volatility transmission more than enhancing SSR.

Several policy implications can be drawn from our experimental results. First, policymakers of food-deficit countries should increase import tariffs on grains and/or subsidize farming production to enhance their SSR if the cost of the policy matches the benefit. Because the expected beneficiaries are consumers and producers with riskaverse preferences, the policy implementation process must evaluate the aggregated benefit for these stakeholders against the cost of boosting food autarky rates. As the 'Identification of potential factors' section makes clear, policymakers must be attentive to the relation between domestic price volatility and/or domestic yield volatility and import price volatility before enacting agricultural autarky policy-raising SSRs may make domestic prices more volatile if the domestic yield of a commodity is more volatile than the rate at which foreign exporting regions produce that commodity. Our results also underscore the importance of substitutive cereal goods, suggesting that consumers respond quickly to price variations. The deeper point here is that a high elasticity of substitution may help to prevent short-term market turmoil, a finding that encourages the regular consumption of foodstuff made from a variety of grains. Put differently, a more balanced consumption of cereals is likely to more effectively buffer volatility waves from international markets. Because our estimation concentrated on short-term volatility spillovers, our research informs best practices for assuaging unforeseen shocks from external markets; however, it does not directly advise how to mollify food poverty fundamentally caused by chronically high food prices.

While our results confirm the ability of self-sufficiency to insulate domestic markets from international ones, the cost-effectiveness of such a directive remains vitally important to consider in policymaking. Imposing tariffs or subsidizing farming operations to boost food self-sufficiency can incur enormous costs. Normalizing balanced food consumption is a much less expensive way to bolster against stormy foreign market shocks. Japan provides a good example of how nationwide food preferences can change. While Japanese citizens consume a wide variety of internationally sourced meals, their pre-war culinary culture was based on traditional Japanese foods, that is, it was primarily based on rice and, to a lesser extent, wheat (such as bread and pasta). This culture began to change when the US donated wheat for Japanese school lunches in 1947. Furthermore, Bellemare's (2014) verification of the association between food prices and social and political unrest implies that such disturbances may be prevented or alleviated by minimizing price conveyance. Although this type of societal burden appears difficult to measure, the overall benefits of prevention may be sizable.

One limitation of this analysis is its simultaneous equation biases, given that local prices could also affect international prices. To deal with this problem, the causality the study establishes needs to be tested using, for instance, the cross-correlation function developed by Hong (2001). However, most of the countries we examined are foodimporting, low-income nations, and the possibility that local prices can alter global cereal prices is very small. 


\section{Appendix}

\section{Robustness test against country selection}

As a robustness check, Table 12 presents the estimation results of the panel regression with the full-country sample. In contrast to what is observed in Table 11, we extended the samples of maize and rice to 26 countries, with 208 observations for both grains. Overall, the coefficients behave similarly to those of the selected developing countries (in Table 11) in terms of statistical significance and signs, except for two coefficients. First, the coefficient of rice's SSR is not significant, even at the $10 \%$ level. This indicates that the SSR of rice does not significantly impact price transmission between the global and local rice markets. Second, the coefficient of rice's consumption on wheat's DCC is significant at the $1 \%$ level. Furthermore, the negative coefficient of rice's consumption suggests that an increase in the consumption of rice will diminish price volatility transmission from global grain markets to local wheat markets. Generally, our results are robust against the change in country selection. However, the changes in the results concerning rice reveal that rice has characteristics distinct from those of both wheat and maize.

\section{Acknowledgements}

The research of the second author is in part supported by a Grant-in-Aid from the Japan Society for the Promotion of Science (Grant Number (A) 18 K14533).

\section{Authors' contributions}

JG and TT designed the research. JG constructed the econometric model and edited the program code for analysis. JG also analyzed and interpreted the data regarding the common determinants of the price volatility transmission of agricultural commodities from international to local markets in developing countries. TT performed the background of the paper and discussed the policy implications of the empirical results. The authors equally contributed to this work. The author(s) read and approved the final manuscript.

\section{Authors' information}

Jin Guo is an Associate Professor of Economics at the Faculty of Economics, Setsunan University. He obtained his Ph.D. from Osaka Prefecture University. His main research focuses on applied time series analysis, empirical finance, data science and open macroeconomics. His recent publications appear in the Journal of Economics and Finance, Applied Economics, Global Finance Journal and Palgrave Communications.

Tetsuji Tanaka is an Assistant Professor at the Department of Economics, Setsunan University, Japan. He holds a Ph.D. in Finance \& Management from School of Oriental and African Studies, University of London. His work focuses on food security, international trade, environmental taxation and modelling. He has published several articles in international peer-reviewed journals such as the Food Policy, Journal of Agriculture Economics and Palgrave Communications.

\section{Availability of data and materials}

The datasets generated and analyzed in this study are available in the Global Information and Early Warning System repository: http://www.fao.org/giews/en/ and Food and Agriculture Organization Corporate Statistical Database (FAOSTAT), accessed at http://www.fao.org/faostat/en/\#home. The data that support the findings of this study can be obtained from the corresponding author upon request.

\section{Competing interests}

The authors declare that they have no competing interests.

Received: 8 March 2019 Revised: 3 December 2019

Accepted: 2 November 2020 Published online: 01 December 2020

\section{References}

Abbott P, Borot de Battisti A (2011) Recent global food price shocks: causes, consequences and lessons for African governments and donors. J Afr Econ 20:112-162

Abdulai A (2000) Spatial price transmission and asymmetry in the Ghanaian maize market. J Dev Econ 63(3):327-349. https:// doi.org/10.1016/S0304-3878(00)00115-2

Anderson K, Tyres R (1984) European community grain and meat policies: effects on international prices, trade and welfare. Eur Rev Agric Econ 11:367-394

Baulch B (1997) Transfer costs, spatial arbitrage, and testing for food market integration. American J Agr Econ 79:477-487

Bellemare M (2014) Rising food prices, food price volatility, and social unrest. Am J Agr Econ 97(1):1-21

Bishwajit G (2014) Food security and food self-sufficiency in China: from the past to 2050. Food Energy Secur 3(2):86-95. https://doi.org/10.1002/fes3.48 
Bishwajit G, Sarker S, Kpoghomou M, Gao H, Jun L, Yin D (2013) Self-sufficiency in rice and food security: a South Asian perspective. Agric Food Secur. https://doi.org/10.1186/2048-7010-2-10

Bollerslev T, Wooldridge JM (1992) Quasi-maximum likelihood estimation and inference in dynamic models with time-varying covariances. Economet Rev 11:143-172. https://doi.org/10.1080/07474939208800229

Cappiello L, Engle RF, Sheppard K (2006) Asymmetric correlations in the global equity and bond returns. J Financ Economet 4:537-572. https://doi.org/10.1093/jjinec/nbl005

Cavaliere G, Phillips PCB, Smeekes S, Taylor AMR (2015) Lag length selection for unit root tests in the presence of nonstationary volatility. Econ Rev 34:512-536. https://doi.org/10.1080/07474938.2013.808065

Ceballos F, Hernandez M, Minot N, Robles M (2017) Grain price and volatility transmission from international to domestic markets in developing countries. World Dev 94:305-320

Clapp J (2017) Food self-sufficiency: making sense of it, and when it makes sense. Food Policy 66:88-96. https://doi.org/10. 1016/j.foodpol.2016.12.001

Conforti P (2004) Price transmission in selected agricultural markets, commodity and trade policy research working paper no. 7. Food and Agriculture Organization, Rome

David LB, Amir R (2017) Stocks and bonds during the gold standard. Econ Lett 159:119-122. https://doi.org/10.1016/j.econlet. 2017.07.021

Delva JG, Loney J (2008) Haiti's government falls after food riots. Reuters Available via Reuters. https://www.reuters.com/ article/us-haiti/haitis-government-falls-after-food-riots-idUSN1228245020080413. Accessed 15 Jan 2019

Dickey DA, Fuller WA (1979) Distribution of the estimators for autoregressive time series with a unit root. J Am Stat Assoc 74: 427-431

Ding Z, Engle RF (2001) Large scale conditional covariance matrix modeling: estimation and testing. Acad Econ Pap 29:157-184

Engle R (2002) Dynamic conditional correlation: a simple class of multivariate generalized autoregressive conditional heteroskedasticity models. J Bus Econ Stat 20(3):339-350. https://doi.org/10.1198/07350010228861847

Engle RF, Sheppard K (2001) Theoretical and empirical properties of dynamic conditional correlation multivariate GARCH. NBER working paper no. w8554. Available via National Bureau of Economic Research. https:/www.nber.org/papers/ w8554. Accessed 10 Oct 2019.

Glosten L, Jagannathan R, Runkle DE (1993) On the relation between the expected value and the volatility of the nominal excess return on stocks. J Financ 48(5):1779-1801. https://doi.org/10.1111/j.1540-6261.1993.tb05128.x

Guillaume P, Kaminski J (2019) Cross country maize market linkages in Africa: integration and price transmission across local and global markets. Agr Econ 50:79-90

Guo J, Tanaka T (2019) Determinants of international price volatility transmissions: the role of self-sufficiency rates in wheatimporting countries. Palgrave Commun 5:124. https://doi.org/10.1057/s41599-019-0338-2

Gutierrez L (2017) Impacts of El Niño-Southern oscillation on the wheat market: a global dynamic analysis. PLoS One 12(6): e0179086. https://doi.org/10.1371/journal.pone.0179086

Hafner FB, Franses HP (2003) A generalized dynamic conditional correlation model: simulation and application to many assets. Economet Rev 28:612-631. https://doi.org/10.1080/07474930903038834

Hatzenbuelhler PL, Abbott PC, Abdoulaye (2017) Price transmission in Nigerian food security crop markets. J Agr Econ 68(1): 143-163. https://doi.org/10.1111/1477-9552.12169

Headey D, Fan S (2008) Anatomy of a crisis: the causes and consequences of surging food prices. Agr Econ 39:375-391. https://doi.org/10.1111/j.1574-0862.2008.00345.x

Hong Y (2001) A test for volatility spillover with applications to exchange rates. J Econom 103:183-224. https://doi.org/10. 1016/50304-4076(01)00043-4

Ivanic M, Martin W (2008) Implications of higher global food prices for poverty in low-income countries. Agr Econ 39(1):405416. https://doi.org/10.1111/j.1574-0862.2008.00347.x

Lagi M, Bertrand KZ, Bar-Yam Y (2011) The food crisis and political instability in North Africa and the Middle East. New England Complex Systems Institute, Cambridge

Lutz C, Kuiper WE, van Tilburg A (2006) Maize market liberalisation in Benin: a case of hysteresis. J Afr Econ 16(1):102-133. https://doi.org/10.1093/jae/ejk008

Magrini E, Montalbano P, Nenci S, Salvatici L (2017) Agricultural (dis)incentives and food security: is there a link? Am J Agr Econ 99:847-871

Minot N (2011) Transmission of world food price changes to markets in Sub-Saharan Africa. IFPRI discussion paper 1059. Available via IFPRI Publications. http://www.ffpri.org/publication/transmission-world-food-price-changes-markets-subsaharan-africa. Accessed 20 Jan 2019.

Moser C, Barrett C, Minten B (2009) Spatial integration at multiple scales: rice markets in Madagascar. Agr Econ 40:281-294. https://doi.org/10.1111/j.1574-0862.2009.00380.x

Mundlak Y, Larson D (1992) On the transmission of world agricultural prices. World Bank Econ Rev 6(3):399-422. https://doi. org/10.1093/wber/6.3.399

Myers RJ (2013) Evaluating the effectiveness of inter-regional trade and storage in Malawi's private sector maize markets. Food Policy 41:75-84. https://doi.org/10.1016/j.foodpol.2013.04.007

Phillips PCB, Perron P (1988) Testing for a unit root in time series regression. Biometrika 75:335-346. https://doi.org/10.2307/2336182

Tanaka T (2018) Agricultural self-sufficiency and market stability: a revenue-neutral approach to wheat sector in Egypt. J Food Secur 6:31-41. https://doi.org/10.12691/jfs-6-1-4

Tanaka T, Hosoe N (2011) Does agricultural trade liberalization increase risks of supply-side uncertainty? Effects of productivity shocks and export restrictions on welfare and food supply in Japan. Food Policy 36:368-377. https://doi.org/10.1016/j. foodpol.2011.01.002

Tanaka T, Hosoe N, Qiu H (2012) Risk assessment of food supply: a computable general equilibrium approach. Cambridge Scholars Publishing, Newcastle upon Tyne 
Trostle R (2008) Global agricultural supply and demand: factors contributing to the recent increase in food commodity prices, Outlook Report WRS-0801. ERS, USDA, Washington DC

von Braun J (2008) Rising food prices: what should be done? IFPRI Policy Brief. International Food Policy Research Institute, Washington, DC

Warr P (2011) Food security vs. food self-sufficiency: the Indonesian case. Crawford School Research Paper no. 2011/04. Available via https://papers.ssrn.com/sol3/papers.cfm?abstract_id=1910356. Accessed 20 Nov 2018

Wooldridge J M (2010) Econometric Analysis of Cross Section and Panel Data. MIT Press: Cambridge MA.

Yang Y, Tyers R (1989) The economic costs of food self-sufficiency in China. World Dev 17(2):237-253

\section{Publisher's Note}

Springer Nature remains neutral with regard to jurisdictional claims in published maps and institutional affiliations.

Submit your manuscript to a SpringerOpen ${ }^{\odot}$ journal and benefit from:

- Convenient online submission

Rigorous peer review

- Open access: articles freely available online

- High visibility within the field

- Retaining the copyright to your article

Submit your next manuscript at $\boldsymbol{\nabla}$ springeropen.com 